\title{
Retraction Note to: Support vector regression methodology for prediction of output energy in rice production
}

\author{
Marziye Yousefi ${ }^{1}$ Benyamin Khoshnevisan ${ }^{1} \cdot$ Shahaboddin Shamshirband ${ }^{2} \cdot$ Shervin $^{\text {Motamedi }}{ }^{3}$. \\ Mohd Hairul Nizam Md. Nasir ${ }^{4} \cdot$ Muhammad Arif $^{2} \cdot$ Rodina Ahmad $^{4}$
}

Published online: 29 May 2019

(C) Springer-Verlag GmbH Germany, part of Springer Nature 2019

\section{Retraction Note to: \\ Stoch Environ Res Risk Assess (2015) 29:2115-2126, https://doi.org/10.1007/s00477-015-1055-z}

The Editor-in-Chief has retracted this article (Yousefi et al. 2015) because validity of the content of this article cannot be verified. This article showed evidence of peer review and authorship manipulation. The authors do not agree to this retraction.

\section{Reference}

Yousefi M, Khoshnevisan B, Shamshirband S et al (2015) Support vector regression methodology for prediction of output energy in rice production. Stoch Environ Res Risk Assess 29:2115. https:// doi.org/10.1007/s00477-015-1055-z

Publisher's Note Springer Nature remains neutral with regard to jurisdictional claims in published maps and institutional affiliations.

The original article can be found online at https:// doi.org/10.1007/s00477-015-1055-z.

Shahaboddin Shamshirband

shamshirband@um.edu.my

1 Department of Agricultural Machinery Engineering, Faculty of Agricultural Engineering and Technology, University of Tehran, Karaj, Iran

2 Department of Computer System and Information Technology, Faculty of Computer System and Information Technology, University of Malaya, 50603 Kuala Lumpur, Malaysia

3 Institute of Ocean and Earth Sciences (IOES), University of Malaya, 50603 Kuala Lumpur, Malaysia

4 Department of Software Engineering, Faculty of Computer System and Information Technology, University of Malaya, 50603 Kuala Lumpur, Malaysia 